\title{
Correction to: The role of eABR with intracochlear test electrode in decision making between cochlear and brainstem implants: preliminary results
}

\author{
Betul Cicek Cinar ${ }^{1,3}$ (D) Mehmet Yarali ${ }^{1} \cdot$ Gamze Atay $^{2} \cdot$ Munir Demir Bajin $^{2} \cdot$ Gonca Sennaroglu $^{1}$. \\ Levent Sennaroglu ${ }^{2}$
}

Published online: 19 June 2020

(c) Springer-Verlag GmbH Germany, part of Springer Nature 2020

\section{Correction to: \\ Eur Arch Otorhinolaryngol (2017) 274:3315-3326 https://doi.org/10.1007/s00405-017-4643-3}

In the original publication of the article, the ethical approval number was published incorrectly as GO 14/195-30. The correct number is GO 14/580-21. Hence, the paragraph under the section "Materials and method" should read as below.

This study was conducted in Hacettepe University Medical School, Department of Ear, Nose and Throat, and Department of Audiology and Speech Pathology. The study was approved by the Ethical Committee of Hacettepe University with registration number of GO 14/580-21).

Publisher's Note Springer Nature remains neutral with regard to jurisdictional claims in published maps and institutional affiliations.

The original article can be found online at https://doi.org/10.1007/ s00405-017-4643-3.

Betul Cicek Cinar

betulcicek01@gmail.com

1 Department of Audiology, Hacettepe University, Ankara, Turkey

2 Department of Otolaryngology, Head and Neck Surgery, Hacettepe University, Ankara, Turkey

3 Hacettepe Üniversitesi Sağlık Bilimleri Fakültesi Odyoloji Bölümü, 06100 Sihhiye/Ankara, Turkey 